\title{
Clinical Study \\ Choice of Antiepileptic Drugs in Idiopathic Generalized Epilepsy: UAE Experience
}

\author{
Taoufik Alsaadi, Haytham Taha, and Fatema Al Hammadi \\ Department of Neurology, Sheikh Khalifa Medical City, Abu Dhabi 51900, UAE \\ Correspondence should be addressed to Taoufik Alsaadi; talsaadi@live.ca
}

Received 22 March 2015; Accepted 5 May 2015

Academic Editor: József Janszky

Copyright ( 2015 Taoufik Alsaadi et al. This is an open access article distributed under the Creative Commons Attribution License, which permits unrestricted use, distribution, and reproduction in any medium, provided the original work is properly cited.

\begin{abstract}
We retrospectively reviewed the electroencephalogram (EEG) reports of patients at our EEG lab from the years 2005-2010 to identify patients referred from the epilepsy clinic, with a confirmed diagnosis of idiopathic generalized epilepsy (IGE) by EEG criteria. We sought to report our experience in UAE of how often patients with IGE are placed on nonspecific antiepileptic drugs (AEDs) before being evaluated at an epilepsy referral clinic. 109 patients with a confirmed diagnosis of IGE based on EEG criteria were identified. When initially seen, 32.11\% were taking a broad-spectrum (specific) AED only, 25.69\% were taking a narrowspectrum (nonspecific) AED, and $15.59 \%$ were placed on various combinations. Of the total patients who were receiving nonspecific AEDs, $35.71 \%$ were seizure-free and $64.28 \%$ were poorly controlled accounting for "pseudointractability status." When converted to broad-spectrum (specific) AEDs, 50\% became well controlled. Furthermore, 26.6\% of patients, who were previously on no AED prior to the clinic visit, became well controlled once placed on specific AED.
\end{abstract}

\section{Introduction}

Idiopathic generalized epilepsy (IGE) comprises a wide variety of epileptic syndromes that are believed to have a strong genetic basis [1] and, as a group, have the highest rate of complete seizure control with the use of broad-spectrum (specific) antiepileptic drugs (AEDs) [2]. Patients with IGE often have a family history of epilepsy that tend to present during childhood or adolescence, although they may not be diagnosed or begin until adulthood (adult onset IGE) [1, 35]. They often have normal intelligence, normal neurological examination, and normal magnetic resonance imaging (MRI) scan. The electroencephalogram (EEG) is the only definitive test to confirm the diagnosis of IGE and, when abnormal, it can be very characteristic of the syndrome, showing generalized spikes and polyspike complexes of $3-4 \mathrm{~Hz}$, or faster frequency, superimposed on a normal EEG background [68]. In general, IGEs respond well to treatment, with 70$80 \%$ being fully controlled. However, not all AEDs are equally effective in treating IGE. The use of narrow-spectrum (nonspecific) AEDs, such as carbamazepine (CBZ) and phenytoin (PHT), either in monotherapy or in combination, is a common wrong practice, which could account for the seemingly difficult to control seizures "pseudointractability" in some reported series [1,9-11].

\section{Methods}

We retrospectively reviewed the EEG reports of all patients seen at our EEG lab in the period from the years 20052010. Patients with EEG criteria consistent with a diagnosis of IGE and referred from the epilepsy clinic at SKMC were identified. For those identified patients, we reviewed their charts, demographic data, workup for epilepsy, age of onset, seizure types, seizure frequency, and their history of AED use, prior to their evaluation at a specialized epilepsy clinic. This clinic was established in mid June 2006, with the objective of providing a comprehensive evaluation for patients with refractory epilepsy. The clinic is managed by an epileptologist along with other neurologists and supportive staff. We recorded the seizure response rate based on the patients' last 6 months clinic visits and compared it to a 6-month period following their evaluation at the epilepsy 
Table 1: Patient demographics.

\begin{tabular}{lc}
\hline Total number & 109 \\
Mean age & 26 \\
Male & 50 \\
Female & 59 \\
Duration of seizures & 10 years \\
(mean) & 16 \\
Age of onset (mean) & $24(22.01 \%)$ \\
Age $>20$ & $96(88.07 \%)$ \\
EEG (IGE alone) & $13(11.92 \%)$ \\
EEG (IGE + Focality) & $17(15.59 \%)$ 1st degree relatives, \\
Family History of seizures, & $5(4.58 \%)$ 2nd degree relatives \\
excluding febrile Sz &
\end{tabular}

clinic and initiation of the "broad-spectrum" AED, if indicated. We have divided the types of AED use into broadspectrum (specific) and narrow-spectrum (nonspecific). It is well established that certain AEDs are more specific than the others for the treatment of IGE, namely, valproate (VPA), lamotrigine (LTG), topiramate (TPM), and levetiracetam (LEV) [10-16]. On the other hand, the group of "nonspecific" AEDs include phenytoin (PHT), carbamazepine (CBZ), oxcarbazepine (OXC), and gabapentin (GBP). We have used the International League Against Epilepsy 1989 classification to classify the different epilepsy types $[17,18]$.

The primary objective of our study was to report our experience in UAE of how often patients with IGE are misdiagnosed and/or mistreated with nonspecific AEDs prior to being evaluated by the epilepsy clinic. The secondary objective was to determine the percentage of patients who become adequately controlled after evaluation at the epilepsy clinic and switched to the "right" choice of AEDs.

\section{Results}

109 patients were identified, 50 males and 59 females, aged 12-56 with mean age of 26 and mean seizure duration of 10 years (Table 1). According to the International League Against Epilepsy classification, 89 patients (81.65\%) had idiopathic generalized epilepsy, 17 patients (15.59\%) had juvenile myoclonic epilepsy (JME), and 3 patients $(2.75 \%$ ) had juvenile absence epilepsy (JAE) (Table 2).

When initially seen, 29 patients $(26.6 \%)$ were not on any AED, and 35 patients (32.11\%) were using specific AED (Table 3); of those, $62.85 \%$ were on VPA, $8.57 \%$ were on TPM, $8.57 \%$ were on LTG, $8.57 \%$ were on LEV, and $11.43 \%$ were on various combinations of specific AEDs (Table 4). On the other hand, 28 patients (25.69\%) were taking narrowspectrum (nonspecific) AEDs (Table 3); of those, 53.57\% were on $\mathrm{CBZ}, 10.71 \%$ were on $\mathrm{PHT}, 3.57 \%$ were on $\mathrm{GBP}$, $3.57 \%$ were on $\mathrm{PB}, 3.57 \%$ were on $\mathrm{OXZ}$, and $25 \%$ were on various combinations of these nonspecific AEDs (Table 5). The remaining 17 patients (15.59\%) were on a combination of both specific and nonspecific AEDs (Table 3).

Of the total 28 patients who were receiving nonspecific AEDs, seizures were adequately controlled in 10 patients
TABLE 2: Epilepsy/seizure types.

\begin{tabular}{lcc}
\hline Epilepsy type & Seizure types & Total patients \\
\hline $\begin{array}{l}\text { Idiopathic generalized } \\
\text { epilepsy with } \\
\text { generalized tonic clonic } \\
\text { seizures }\end{array}$ & $(89)$ 100\% GTCs & $89(81.65 \%)$ \\
\hline $\begin{array}{l}\text { Juvenile myoclonic } \\
\text { epilepsy }\end{array}$ & $\begin{array}{c}15(88 \%) \text { GTCs } \\
17(100 \%) \text { myoclonic }\end{array}$ & $17(15.59 \%)$ \\
\hline $\begin{array}{l}\text { Juvenile absence } \\
\text { epilepsy }\end{array}$ & $\begin{array}{c}3(100 \%) \text { GTCS } \\
(100 \%) \text { absences }\end{array}$ & $3(2.75 \%)$ \\
\hline
\end{tabular}

TABle 3: Prior AED use.

\begin{tabular}{lc}
\hline Patients on no prior AED & $29(26.60 \%)$ \\
Patients on specific AED & $35(32.11 \%)$ \\
Patients on nonspecific AED & $28(25.69 \%)$ \\
$\begin{array}{l}\text { Patients on combination of specific and } \\
\text { nonspecific AED }\end{array}$ & $17(15.59 \%)$ \\
\hline
\end{tabular}

TABLE 4: Prior adequate AED use.

\begin{tabular}{lc}
\hline Patients on specific AED & 35 patients \\
\hline (1) Valproate & $22(62.85 \%)$ \\
(2) Topiramate & $3(8.57 \%)$ \\
(3) Lamotrigine & $3(8.57 \%)$ \\
(4) Levetiracetam & $3(8.57 \%)$ \\
(5) Combination & $4(11.43 \%)$ \\
\hline
\end{tabular}

TABle 5: Prior nonspecific AED use.

\begin{tabular}{lc}
\hline Patients on nonspecific AED & 28 patients \\
\hline (1) Carbamazepine & $15(53.57 \%)$ \\
(2) Phenytoin & $3(10.71 \%)$ \\
(3) Gabapentin & $1(3.57 \%)$ \\
(4) Phenobarbital & $1(3.57 \%)$ \\
(5) Oxcarbazepine & $1(3.57 \%)$ \\
(6) Combination & $7(25.0 \%)$ \\
\hline
\end{tabular}

TABle 6: Treatment response in nonspecific AED group.

\begin{tabular}{lcc}
\hline 28 patients & $\begin{array}{c}\text { Prior nonspecific } \\
\text { AED }\end{array}$ & $\begin{array}{c}\text { Change adequate } \\
\text { AED }\end{array}$ \\
\hline $\begin{array}{l}\text { Adequately controlled } \\
\text { seizures }\end{array}$ & $10(35.71 \%)$ & $14(50.0 \%)$ \\
\hline $\begin{array}{l}\text { Poorly controlled } \\
\text { seizures }\end{array}$ & $18(64.28 \%)$ & $8(28.57 \%)$ \\
\hline \begin{tabular}{l} 
Missed to follow up \\
\hline
\end{tabular}
\end{tabular}

(35.71\%), while 18 patients $(64.28 \%)$ had poorly controlled seizures (Table 6). When these patients' AED regimens were changed from nonspecific to a specific AED, 14 patients $(50.0 \%)$ became fully controlled, 8 patients $(28.57 \%)$ appeared to be truly intractable to all medication regimens, and 6 patients $(21.42 \%$ ) have missed followup (Table 6 ). 


\section{Discussion}

To our knowledge, this is the first study in the MiddleEast region that demonstrates the percentage of IGE patients who seemingly have difficult to control seizures (pseudointractable), but, in reality, they were using "nonspecific" AEDs. Our findings underscore the importance of establishing accurate diagnosis based on syndromic classification. As a matter of fact, the International League Against Epilepsy explicitly recommends that the classification of syndromes be "used daily in communication between colleagues" and be the "subject of clinical trials and other investigations."

Our findings in our region are similar to other series, where $30 \%$ of patients with IGE were on nonspecific medications and $65 \%$ of them had poorly controlled seizures. When switched to more specific AEDs, $50 \%$ became seizure-free. This shows the importance of thorough and comprehensive evaluation of patients with difficult to control seizures before they are deemed refractory to AEDs. Interestingly, however, $34 \%$ of IGE patients treated with "nonspecific" drugs, such as CBZ or PHT, were seizure-free. Of note, all these patients had GTCs as the predominant seizure type, and none of them had associated absence or myoclonic seizures. It is well established that these latter seizure types may worsen with the use of certain AEDs, whereas GTCs may respond well to a narrowspectrum (nonspecific) AEDs $[2,11,16]$.

Our study has clinical implications as most patients with generalized tonic clonic (GTC) seizures are assumed to have focal seizures with secondary generalization, especially if their seizures start in adult life [19]. Indeed, $22 \%$ of our IGE patients had their seizures beginning after the age of 20 . This emphasizes the need to keep an open mind approach, when evaluating these patients, and to consider using broadspectrum AEDs if in doubt about the underlying syndromic diagnosis.

We realize that our study has its limitations. It is relatively small, single center, and retrospective. Some patients were missed to follow-up. Moreover, it has a selection bias, as specialty epilepsy clinics tend to evaluate patients that are doing poorly. Indeed, and as illustrated in our cohorts, a significant proportion of our patients were doing poorly at the time of referral, and $28.57 \%$ of them have remained intractable despite a trial of several AEDs.

\section{Conclusion}

Our findings confirm the previous views that a poor choice of AED is still the main cause of IGEs that are seemingly difficult to control and show the importance of establishing specialized epilepsy clinics to evaluate these patients and make the appropriate changes. In our region, the inappropriateness of some AEDs for IGE is still not well recognized in a significant proportion of our patients.

\section{Conflict of Interests}

The authors declare that there is no conflict of interests.

\section{References}

[1] C. Marini, M. A. King, J. S. Archer, M. R. Newton, and S. F. Berkovic, "Idiopathic generalised epilepsy of adult onset: clinical syndromes and genetics," Journal of Neurology Neurosurgery and Psychiatry, vol. 74, no. 2, pp. 192-196, 2003.

[2] S. R. Benbadis, W. O. Tatum, and M. Gieron, "Idiopathic generalized epilepsy and choice of antiepileptic drugs," Neurology, vol. 61, no. 12, pp. 1793-1795, 2003.

[3] H. O. Luders, "Classification of epileptic seizures and epilepsies," in Textbook of Epilepsy Surgery, H. O. Luders, Ed., p. 245, Informa UH, London, UK, 2008.

[4] A. Nicolson, D. W. Chadwick, and D. F. Smith, "A comparison of adult onset and 'classical' idiopathic generalized epilepsy," Journal of Neurology, Neurosurgery and Psychiatry, vol. 75, no. 1, pp. 72-74, 2004.

[5] F. Andermann and S. F. Berkovic, "Idiopathic generalized epilepsy with generalized and other seizures in adolescence," Epilepsia, vol. 42, no. 3, pp. 317-320, 2001.

[6] S. Yenjun, A. S. Harvey, C. Marini et al., "EEG in adult-onset idiopathic generalized epilepsy," Epilepsia, vol. 44, pp. 252-256, 2003.

[7] J. M. Rho, R. Sankar, and J. E. Cavazos, Epilepsy: Scientific Foundations of Clinical Practice, Marcel Dekker, New York, NY, USA, 2004.

[8] R. Mohanraj and M. J. Brodie, "Outcomes of newly diagnosed idiopathic generalized epilepsy syndromes in a non-pediatric setting," Acta Neurologica Scandinavica, vol. 115, no. 3, pp. 204208, 2007.

[9] R. H. Mattson, "Drug treatment of uncontrolled seizures," Epilepsy Research, no. 5, pp. 29-35, 1992.

[10] A. Nicolson, R. E. Appleton, D. W. Chadwick, and D. F. Smith, "The relationship between treatment with valproate, lamotrigine, and topiramate and the prognosis of the idiopathic generalised epilepsies," Journal of Neurology, Neurosurgery and Psychiatry, vol. 75, no. 1, pp. 75-79, 2004.

[11] E. Perucca, "The management of refractory idiopathic epilepsies," Epilepsia, vol. 42, supplement 3, pp. 31-35, 2001.

[12] V. Biton, G. D. Montouris, F. Ritter et al., "A randomized, placebo-controlled study of topiramate in primary generalized tonic-clonic seizures," Neurology, vol. 52, no. 7, pp. 1330-1337, 1999.

[13] M. Mazurkiewicz-Bełdzińska, M. Szmuda, and A. Matheisel, "Long-term efficacy of valproate versus lamotrigine in treatment of idiopathic generalized epilepsies in children and adolescents," Seizure, vol. 19, no. 3, pp. 195-197, 2010.

[14] D. Atakli, D. Sözüer, T. Atay, S. Baybas, and B. Arpaci, "Misdiagnosis and treatment in juvenile myoclonic epilepsy," Seizure, vol. 7, no. 1, pp. 63-66, 1998.

[15] J. P. Leach and M. J. Brodie, "Lamotrigine clinical use," in Antiepileptic Drugs, pp. 889-895, Raven Press, New York, NY, USA, 1995.

[16] S. R. Benbadis, "Practical management issues for idiopathic generalized epilepsies," Epilepsia, vol. 46, no. 9, pp. 125-132, 2005.

[17] R. S. Fisher, W. van Emde Boas, W. Blume et al., "Epileptic seizures and epilepsy: definitions proposed by the International League Against Epilepsy (ILAE) and the International Bureau for Epilepsy (IBE)," Epilepsia, vol. 46, no. 4, pp. 470-472, 2005. 
[18] "Proposal for revised classification of epilepsies and epileptic syndromes. Commission on Classification and Terminology of the International League Against Epilepsy," Epilepsia, vol. 30, no. 4, pp. 389-399, 1989.

[19] S. R. Benbadis, "Observations on the misdiagnosis of generalized epilepsy as partial epilepsy: causes and consequences," Seizure, vol. 8, no. 3, pp. 140-145, 1999. 


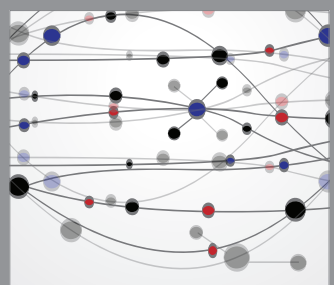

The Scientific World Journal
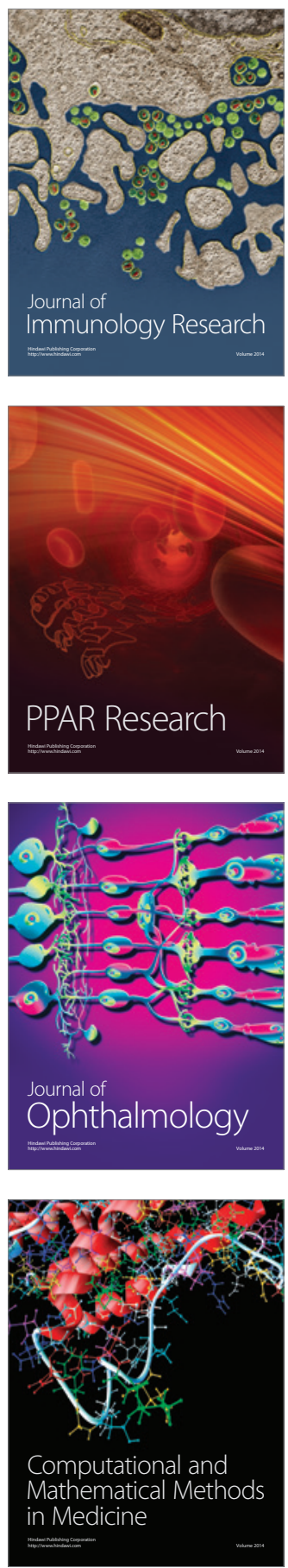

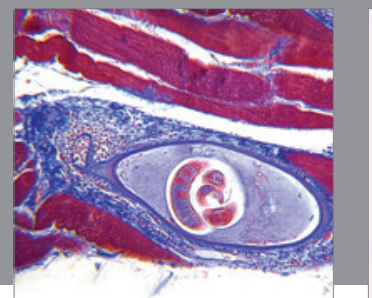

Gastroenterology

Research and Practice
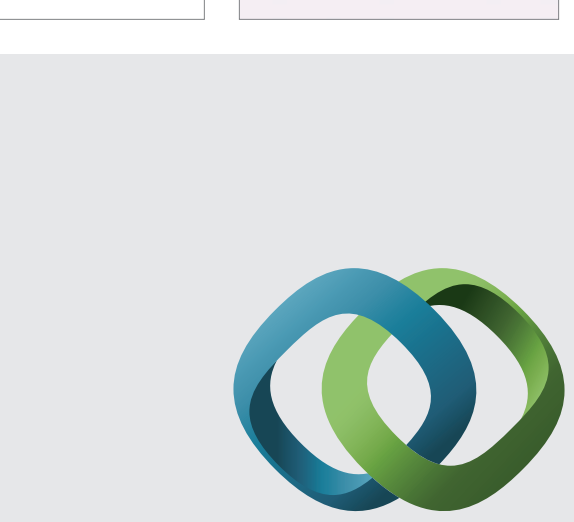

\section{Hindawi}

Submit your manuscripts at

http://www.hindawi.com
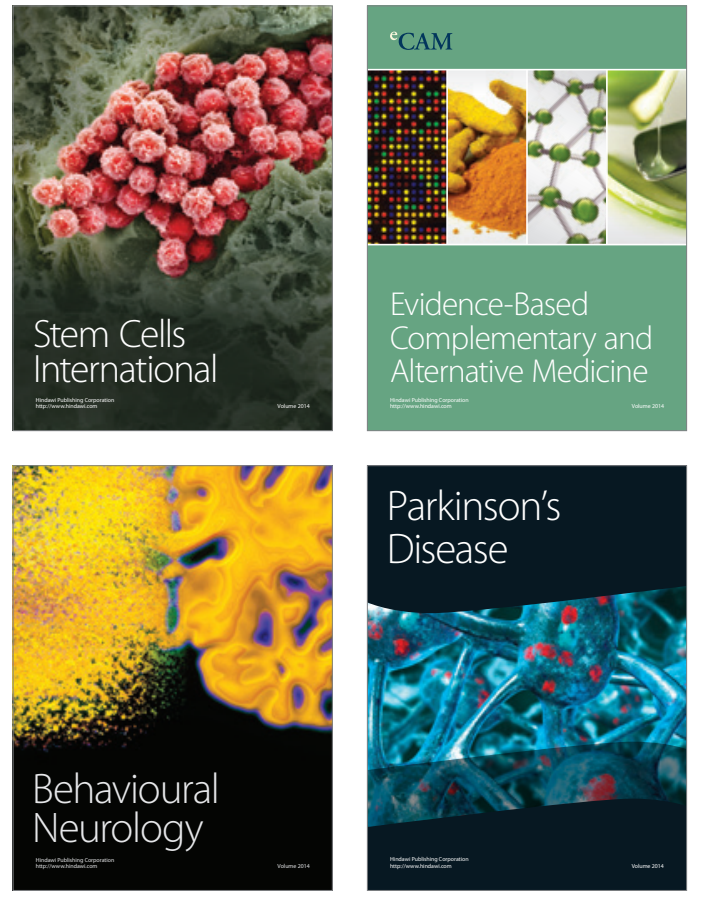
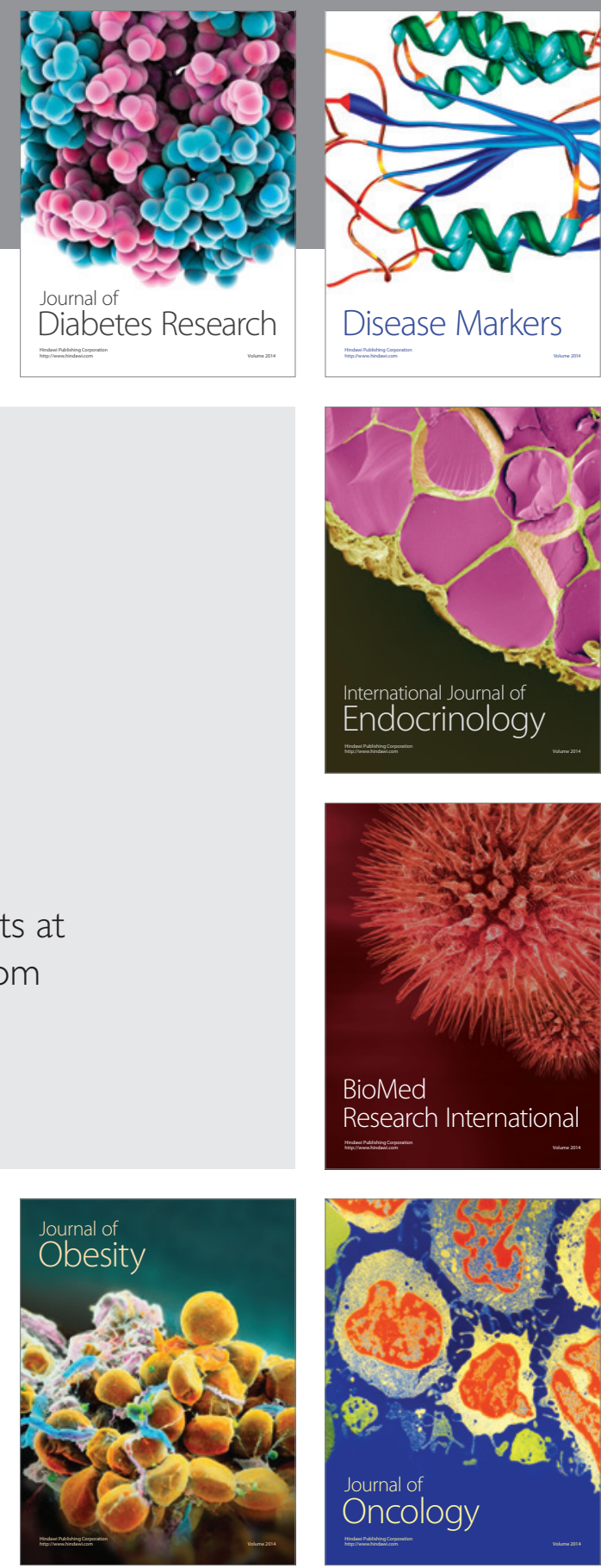

Disease Markers
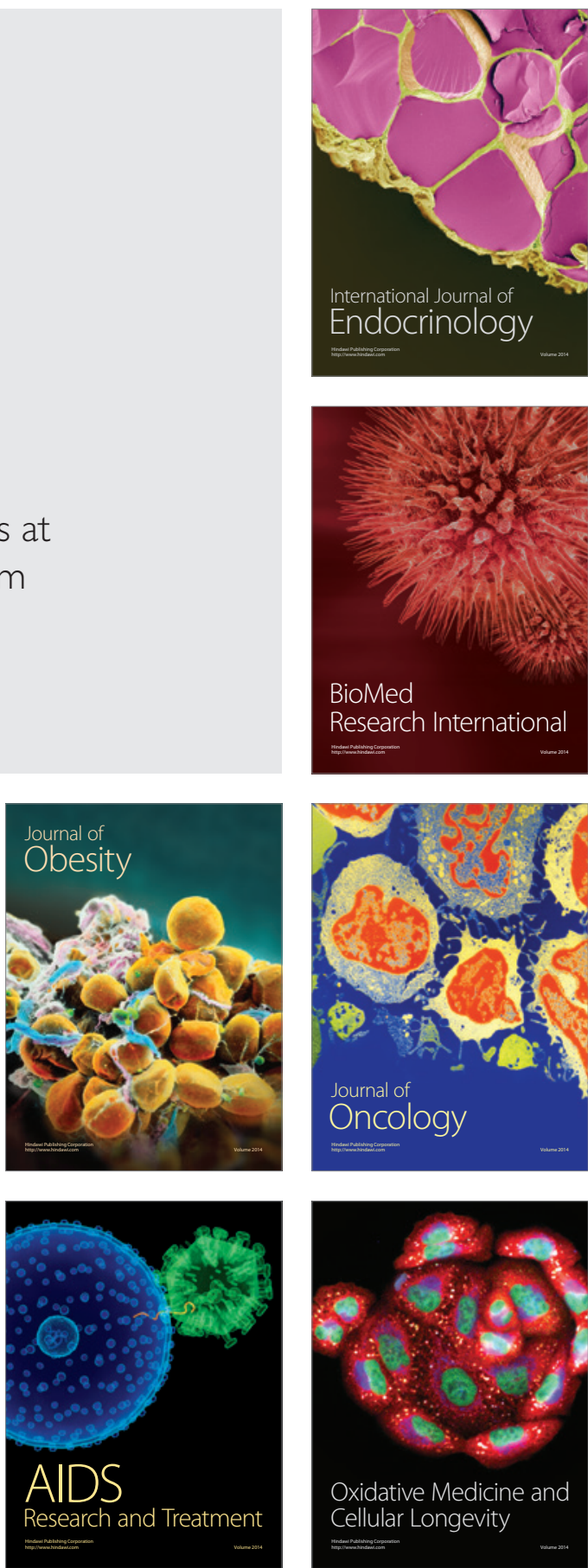